\title{
Effects of location on the physico-chemical properties of water in the Matatiele Local Municipality, South Africa
}

\author{
L. T. Polasi ${ }^{1,2}$, M. D. V. Nakin ${ }^{2}$, Z. Magayiyana ${ }^{1}$ \\ \& C. M. Musampa ${ }^{1}$ \\ ${ }^{1}$ Department of Biological and Environmental Sciences, \\ Walter Sisulu University, South Africa \\ ${ }^{2}$ Risk and Vulnerability Science Centre, \\ Walter Sisulu University, South Africa
}

\begin{abstract}
Water security is one of the crucial global issues because of climate change. South Africa is a water scarce country and it is currently facing challenges in water provision, sanitation and supply. The aim of the study was to investigate how location affects the physico-chemical properties of water in the Matatiele Local Municipality. This was achieved by identifying water sources in three categories of location (rural, peri-urban and urban) which are mostly used and measuring their physico-chemical properties of water. They were measured using $\mathrm{HACH}$ 2100Q (V1.03/9) for turbidity and HQ40d (MULTI V2.3.0.730) for $\mathrm{pH}$, dissolved oxygen and conductivity in each of the water sources at each category. Within each category, six areas were randomly selected. ArcGIS (version10.3) was used to map the water sources. Chi-squared tests revealed that turbidity was significantly highest in rural areas, and lowest in urban areas. In wells, dams and rivers, turbidity was found to be out of WHO drinking water guidelines. Similarly, $\mathrm{pH}$ values were out of the WHO drinking water guidelines in wells for rural areas, tanks for urban areas and in springs and wells in the peri-urban areas. Dissolved oxygen and conductivity varied among the three categories with no clear patterns. These results highlight a need for the Department of Water and Sanitation authorities to give much attention to the water quality in rural and peri-urban areas. Keywords: water sources, water quality, pH, turbidity, dissolved oxygen, electrical conductivity.
\end{abstract}




\section{Introduction}

Water is identified as one of the most important natural resources because it is viewed as a key to prosperity and wealth [1]. Water security is defined as a situation where people and communities have reliable access to water to meet their different needs Page et al. [2]. Such access to water is inclusive of both present and future needs. The water that they have access to must be both healthy and suitable for drinking purposes [2]. What determines water security is the ability of households to obtain the required quantity of suitable quality water for drinking, personal hygiene, other domestic purposes and other economic activities [3]. Drinking water should be suitable for human consumption and also for washing or showering and domestic food preparation (Asadullah Nisa and Khan [4]).

Poor water quality continues to pose a major threat to human health [5]. Water, sanitation and hygiene have important impacts on both health and disease. Many water sources in developing countries are unhealthy because they contain harmful physical, chemical and biological agents [6]. Waterborne diseases are caused by pathogenic microorganisms that most commonly are transmitted in contaminated fresh water. Infection commonly results during bathing, washing, drinking, in the preparation of food, or the consumption of food thus infected [7].

The provision of high-quality drinking water is a focal point for improving human health of a community by preventing the spread of water born disease [8]. Water quality for drinking is determined by various indicators [9]. Physicochemical parameters of water are important to determine the quality of drinking water as according to [10]. Hence the aim of the study was to assess how the location affects physico-chemical properties of water in the Matatiele Local Municipality.

\section{Materials and methods}

Study area was categorized into rural, peri-urban and urban area. Ten (10) water samples in different water sources in each category were randomly collected. Water sample were kept in a cooler box with ice packs after collection until they were tested and analyzed. For this study, only $\mathrm{pH}$, turbidity, dissolved oxygen and conductivity were tested. $\mathrm{pH}$ was determined using HQ40d (MULTI V2.3.0.730) in room temperature. This device was calibrated with $\mathrm{pH} 7$ and buffer 4 . The same device was used to determine dissolved oxygen and conductivity using different probes respectively. HACH 2100Q (V1.03/9) was used to determine turbidity. Matatiele Local Municipality is approximately $4,352 \mathrm{~km}^{2}(435,230.9 \mathrm{ha})$ and is located in the northern part of the Eastern Cape Province in South Africa.

\section{Results}

The wells in figures 2 and 3 have been identified in a rural area and they are used for domestic purposes. The well in figure 2 is surrounded a wall built by mud and stones and is not covered on top. It is completely open or unprotected just like the one in figure 3 and animals might have access to these wells. 


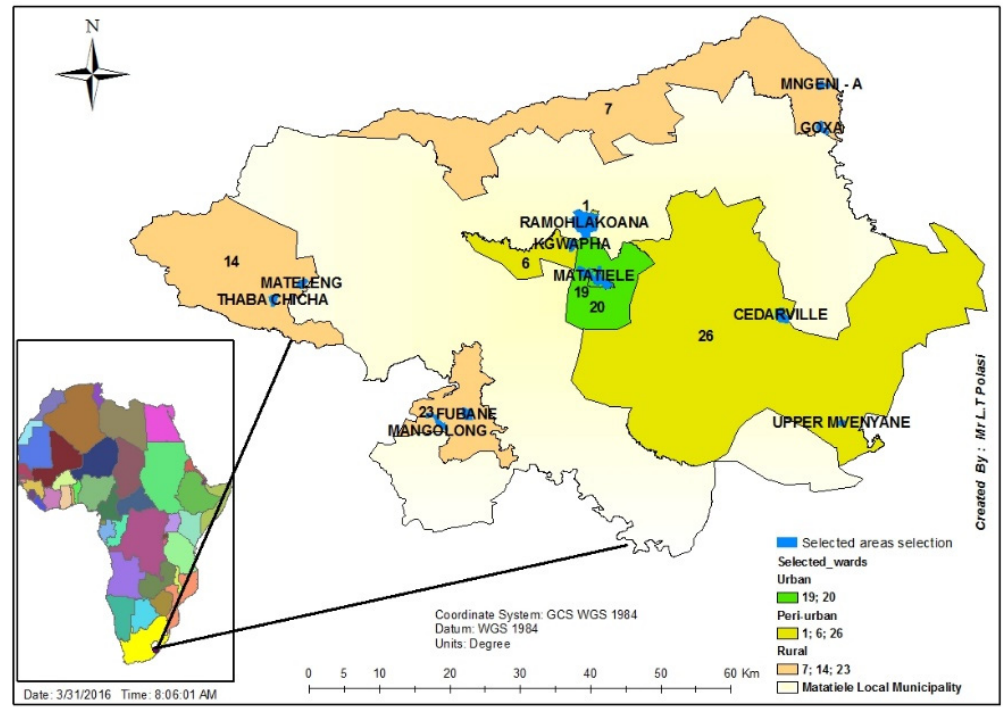

Figure 1: Matatiele Local Municipality map.

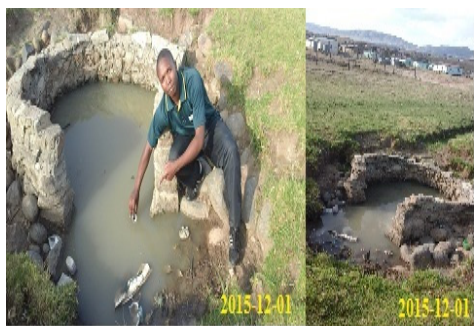

Figure 2: Mangolong well.

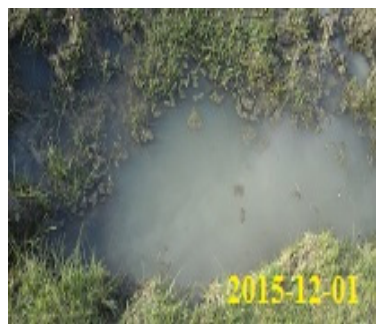

Figure 3: Fobane well.

Unprotected wells are usually common in rural areas. Figure 4 shows a well which people use for drinking water in a rural area in Matatiele. People share this well with animals. Mvenyane is one of the areas found in peri-urban in Matatiele. They have taps and wells as their water sources. Some wells those wells (figure 5) are built by sticks, stones and pieces of corrugated iron. Although it is partially covered, animals also drink from this well.

A spring or groundwater (figure 6) which has been redirected or rechanneled by a steal pipe to make it more accessible to the community was identified in a peri-urban area. This water source has water throughout the year. However, people who uses this water reported that it is salty (hard water). The well in figure 7 was found in a peri-urban area called Khoapa. It is built with a barrel which is cut into two halves and one half was fitted in a hand-dug well. This barrel is rusty in its 


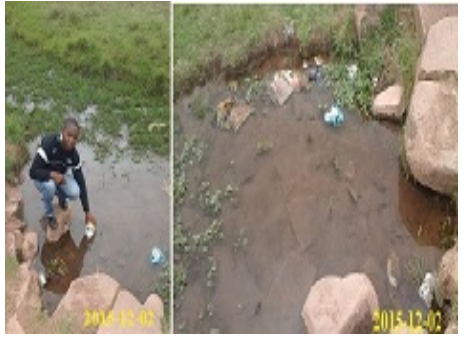

Figure 4: Mateleng well.

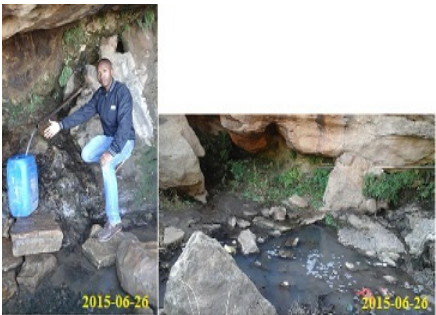

Figure 6: Khoapa spring (Khohlong).

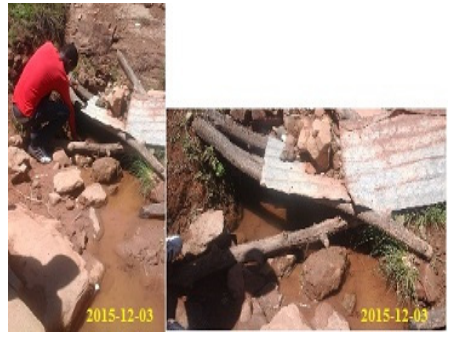

Figure 5: Mvenyane well.

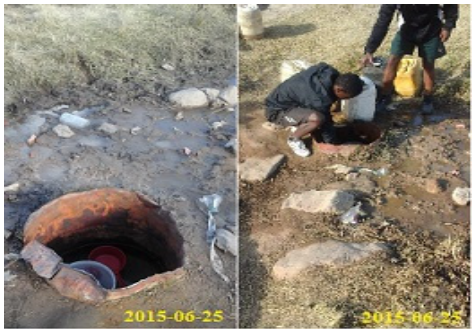

Figure 7: Khoapa well (Pontong).

inside walls where it is in contact with the same water that people are using. This well is unprotected and it is easy for animals to use for drinking too.

Figure 8 shows a well which is located in a peri-urban area and is being used for drinking water. This well is built by stones and covered with pieces of corrugated iron and old rusty wheelbarrow body. However, animals can still drink from this well (figure 8 - right) and that means it is unprotected. These communal taps in figure 9 were identified in a peri-urban area in Matatiele. Some of the taps

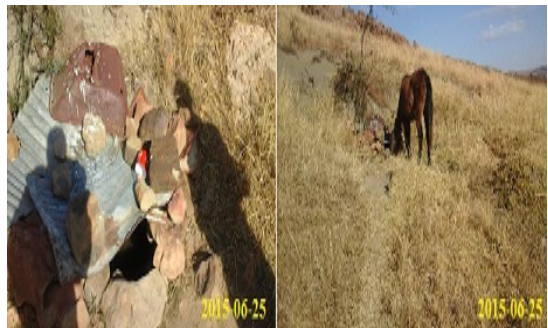

Figure 8: $\quad$ Ramohlakoana well (Mafiri).

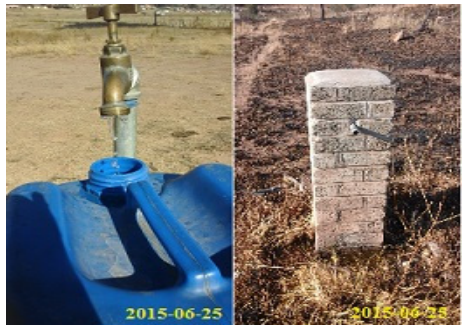

Figure 9: Khoapa tap. 
were found with no tap head and therefore there was no water coming from them. Others were in good condition.

The $\mathrm{pH}$ of different water sources in rural, peri-urban and urban areas was tested and results are shown in figure 10. Highest $\mathrm{pH}$ was found in rivers in rural areas but it was within WHO drinking water guidelines and lowest was found in tanks in urban areas and was out of WHO drinking water guidelines.

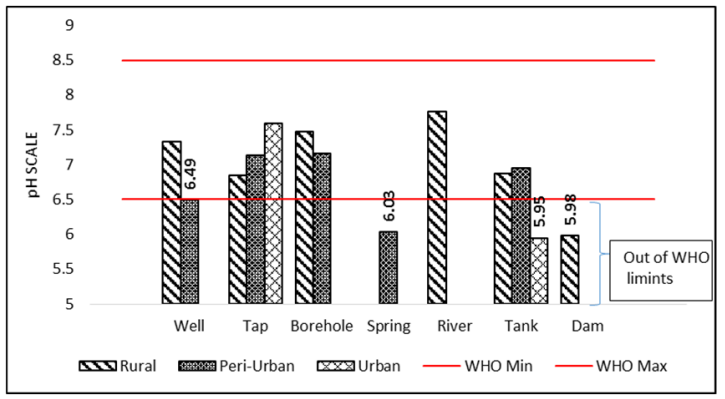

Figure 10: Mean $\mathrm{pH}$ of different water sources with standard deviation of $(0.90$ urban, 0.61 peri-urban and 0.72 rural).

Results in figure 11 show turbidity of water sources in rural, peri-urban and urban areas in Matatiele. Rivers in rural area were the most turbid and taps in urban areas were least turbid.

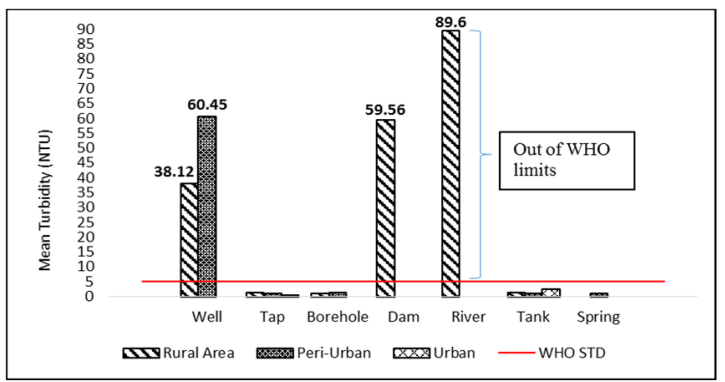

Figure 11: Mean turbidity of different water sources with standard deviation of (0.86 urban, 31.43 peri-urban and 30.96 rural).

Dissolved oxygen of water sources in rural, peri-urban and urban areas in Matatiele was measured and the results are shown in figure 12. This chemical property showed no distinct pattern in all categories.

Conductivity (figure 13) in rural, peri-urban and urban areas in Matatiele did not have a clear trend and it varied in all three categories 


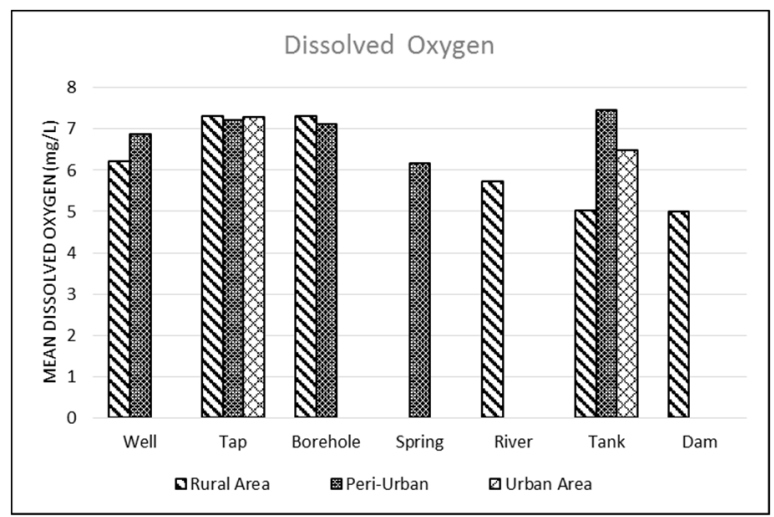

Figure 12: Mean dissolved oxygen of different water sources with standard deviation of (0.36 urban, 0.43 peri-urban and 1.06 rural).

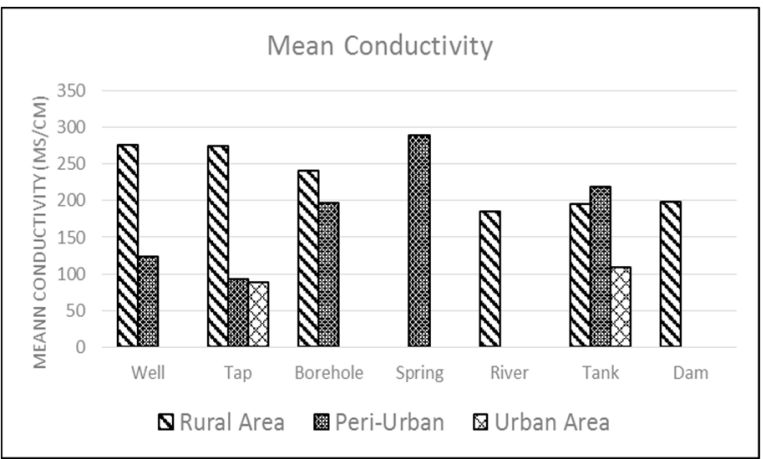

Figure 13: Mean conductivity of different sources with the standard deviation of (89.78 urban, 71.71 peri-urban and 12.50 rural).

Selected water sources were mapped using ArcGIS (v10.3) and are shown in figure 14. The blue pointer represents a well, red one represents a tap, green one represents a river, purple one represents a spring and a blue circle represents a borehole. 


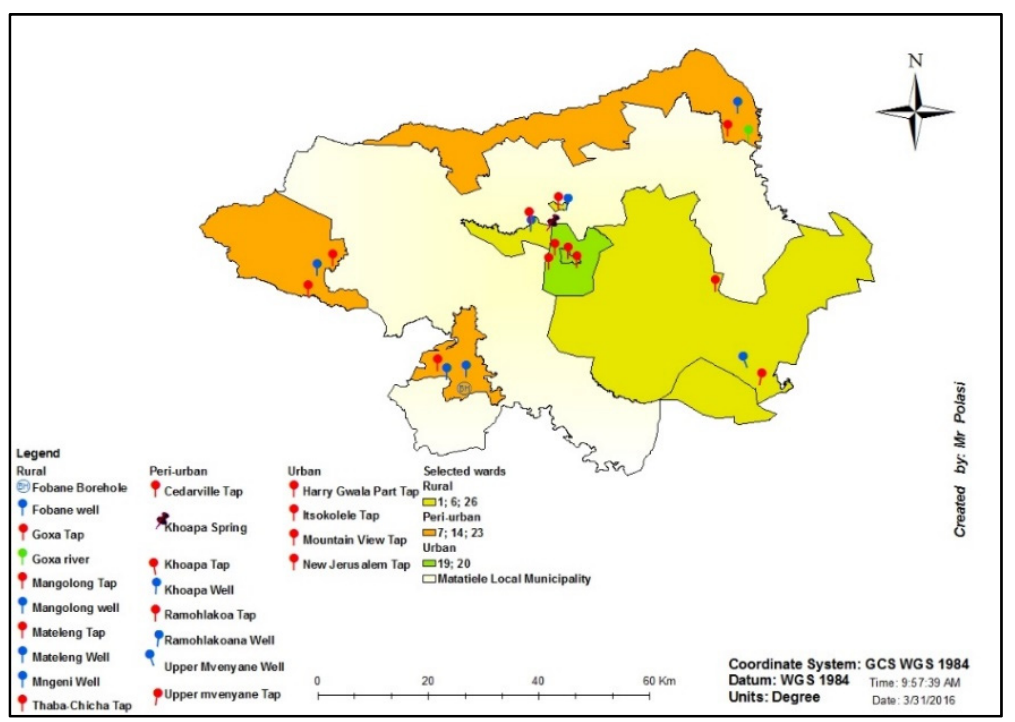

Figure 14: Map of the selected water sources in the Matatiele Local Municipality.

\section{Discussion}

Water samples were tested in three categories (urban, peri-urban and rural area) and results are displayed in figure $10 . \mathrm{pH}$ is one of the important parameter on determining water quality. It is measured in a scale of $1-14$ and 7 being the neutral. Water becomes acidic as $\mathrm{pH}$ decreases from 7 downwards and it becomes alkalinity as $\mathrm{pH}$ increases from 7 up to 14 . At low $\mathrm{pH}$, water may taste sour while at high $\mathrm{pH}$ water taste bitter or soapy [11]. The acceptable range of $\mathrm{pH}$ in water lies between 6.5 and $8.5 \mathrm{pH}$ for drinking purposes [12]. Wells and springs in periurban, tanks in urban and dams in rural areas were lied out of WHO acceptable limits of drinking water. No water source found with the $\mathrm{pH}$ above 8.5. All those water sources which were out of WHO acceptable limits were less than 6.5 and this means they have acidic water. Then this means that water from these sources are not of good quality and are not supposed to be consumed by human as far as $\mathrm{pH}$ is concerned. Other water sources were within WHO acceptable limits and this means that it is safe to drink that water with respect to $\mathrm{pH}$ level.

This water may cause or pose health risks if it is used for drinking and other domestic uses. Water with a low $\mathrm{pH}$ level may cause corrosion in galvanized or copper pipes and this could lead to an increase in the amount of heavy metals in water [11]. There are no health consequences attributed to $\mathrm{pH}$ of water, except at extreme values. The direct health effects of low and high $\mathrm{pH}$ levels include acid and alkali burns, respectively [11].

Results revealed some effect of location on physico-chemical properties of these water sources which are common in all categories. Even though tap $\mathrm{pH}$ lied 
with WHO acceptable limits, it had significant difference between a tap in rural and urban area with mean $\mathrm{pH}(6.85: \sigma 0.72)$ and $(7.85: \sigma 0.90)$ respectively. The possibility is that municipality or water and sanitation authorities focuses more and the quality of water being supplied to communities in urban area than in rural and peri-urban. Similarly, tanks in peri-urban and urban areas had with mean $\mathrm{pH}$ (6.9: $\sigma 0.6) 1$ and (5.95: $\sigma 0.61)$ respectively. Possible reason for this variation may be that the activities taking place in urban might be emitting lot of carbon into the atmosphere which may possibly come back as an acid rain. Hence rain water in this area has low $\mathrm{pH}$. However, ANOVA single factor showed no significant difference ( $\mathrm{p}$-value $0.191>\mathrm{Q} 0.05$ ) between these three categories.

Turbidity is a standard drinking water quality indicator which is related to the amount and physical characteristics of suspended particles but does not indicate the type or source of particles Hsieh et al. [13]. The standard recommended maximum turbidity limit, set by [10] for drinking water is less than or equal to 5 nephelometric turbidity units (NTU). In figure 11, wells, dams and rivers in rural and wells in peri-urban were found to be out of WHO drinking water acceptable limits. These water sources are not good for drinking turbidity wise and people who drink water from these water sources may have health problems. They may suffer from water-borne diseases [13]. Other water sources in all categories were below 5 NTU and this means as far as turbidity is concerned, they are good for drinking.

WHO states that the more the water is turbid, the greater the chances of pathogens' growth because they will be protected from the effect of disinfectants [10]. Low turbidity minimizes the potential of infectious diseases Momba et al. [14]. Hence it is not safe to consume high turbid water because it would be a health risk due to microorganism as the probable part in it [4]. We can safely say that location had no effect on $\mathrm{pH}$ of all taps and tanks which were common water sources in all categories because they were within WHO acceptable limit and showed no significant difference. However, wells in peri-urban were found to be more turbid than those in rural area. This might be as a results of introduction of taps in peri-urban. So people have neglected wells. Unlike in rural areas where majority of people still depend on wells and they still take care of them. Hence the level of turbidity in wells is lower in rural areas than in peri-urban. Nevertheless, ANOVA single factor revealed that there is no significant difference between the three categories because the p-value $0.284>\mathrm{Q} 0.05$.

One of the parameters which is used to determine water quality is dissolved oxygen. According to [10], there is no standard limit of how much dissolved oxygen must be in water to safely say that water is of good quality. However, water must have certain amount of dissolved oxygen. All water sources varied in the amount of dissolved oxygen in figure 12 in all categories. Then this means that in terms of dissolved oxygen, all sampled water sources have good water quality for drinking and it is safe to consume it. Location of these water sources showed little or no effect of physico-chemical properties because there is no distinct pattern which a conclusion to say the location had an effect and ANOVA single factor showed no significant difference because p-value $0.134>\mathrm{Q} 0.05$. 
In figure 13, effects of location on conductivity is evident. Wells in rural areas had high and in peri-urban had low conductivity with the mean of $(275.75 \mu \mathrm{s} / \mathrm{cm}$ : $\sigma 12.50)$ and $(123.33 \mu \mathrm{s} / \mathrm{cm}: \sigma 71.71)$ respectively. Similarly, conductivity was significantly high in taps in rural areas and low in urban and peri-urban with the mean of $(274.95 \mu \mathrm{s} / \mathrm{cm}: \sigma 12.50),(87.85 \mu \mathrm{s} / \mathrm{cm}: \sigma 89.78)$ and $(92.48 \mu \mathrm{s} / \mathrm{cm}: \sigma 71.71)$ respectively. Overall, conductivity was found to be highest in rural and lowest in urban areas. ANOVA single factor revealed a significant difference ( $p$-value $0.0069<\mathrm{Q} 0.05$ ) between these three categories. Therefore, the location had an effect on electrical conductivity.

Conductivity is the ability of any medium to carry an electric current Rahmanian et al. [15]. In this case, water is a medium which allows electrical current flow. Electric current through water is facilitated by presence of dissolved solids such as calcium, chloride, and magnesium in water. Hence higher conductivity value leads to high mineral contents in water. This is also a parameter for determining water quality even though WHO does not have specific or objectable limit for it.

Conductivity does not have direct impact on human health. However, it is determined for several purposes such as determination of mineralization rate and estimating the amount of chemical reagents used to treat water Kavcar et al. [16]. High conductivity may lead to lowering the aesthetic value of the water by giving mineral taste to it [16]. It is critical therefore to monitor conductivity of water for the industries and farmers because high conductivity may cause corrosion of metal surface of equipment such as boiler. It is also applicable to home appliances such as water heater system [15].

\section{Conclusion}

In terms of $\mathrm{pH}$, most water sources were within WHO acceptable limits and few of them were out of those limits. Those water sources such as dams which were out of acceptable limits are not mostly used by many people. Water from tanks in urban areas, wells and springs in peri-urban and dams in rural areas is not good for drinking because they were out of WHO drinking water acceptable limits. Taps were all within WHO acceptable, therefore it is safe to drink it regardless of their location. With respect to turbidity, it is not safe to drink water from wells, dams and rivers in rural areas and wells in peri-urban because they were found to be out of WHO acceptable drinking water limits. Other sources such as taps, boreholes, tanks and springs were perfectly within WHO drinking water limits regardless of their location.

Location had little or no effect on dissolved oxygen in all the sampled water sources. WHO does not specify a limit for dissolved oxygen, it is then safe to drink water from all those water sources regardless of their location because they showed no significant difference. Results revealed that location does affect conductivity. In this case, conductivity was highest in rural and lowest in urban areas. Even though conductivity has no direct impact on human health, literature states that it is wise to use water with low conductivity. 
These results highlight the need for municipality and authorities from Department of Water and Sanitation to share their focus equally among rural, periurban and urban areas regarding the provision of quality water for drinking. In rural areas, the renovation and constant cleaning of storage tanks and water pipes is recommended so that the water will remain clean and usable. Awareness and training about household water purification methods would help a lot in terms of making sure that people from all three categories have the same quality water for drinking. Protecting some water sources such as open wells in rural and peri-urban areas from pollution and being used by animals is highly recommended.

\section{Acknowledgements}

We acknowledge the financial support from the Department of Science and Technology (DST), National Research Foundation (NRF) and Risk and Vulnerability Science Center (RVSC).

We would like to pass a word of gratitude to Walter Sisulu University for its help when it comes to logistics in making sure that this study was a success.

We also extend our sincere word of thanks to Matatiele Local Municipality for their help in the process of data collection. Lastly, we thank everyone who gave a hand to make this study a great success.

\section{References}

[1] Asare, Y. B. O. Household Water Security and Water Demand in the Volta Basin of Ghana. PhD Thesis, 2004.

[2] Page, S., Mitchell, K., Steel, L., Randell, T., Gallagher, S. \& Halse, S. Assessment of the security and sustainability of water supply in Grahamstown. Honours degree, Rhodes University, 2010.

[3] Ratnaweera, P. Modelling household water Security, paper presented at a 3day Workshop held at the Haus Khaus campus of the Indian Institute of Technology Delhi. Water Resources Development. 3, 12-24, 1999.

[4] Asadullah, Nisa, K. \& Khan, S. I. Physico-chemical properties of drinking water available in educational institutes of Karachi City. Science, Technology and Development. 32, 28-33, 2013.

[5] Hatami, H. Importance of Water and Water-Borne Diseases: On the Occasion of the World Water Day (March 22, 2013). International Journal of Preventive Medicine. 14, 246-245, 2013.

[6] Cheesbrough, M. Medical Laboratory Manual for Tropical Countries, London, University Press, Cambridge, 1984.

[7] Nwachuku, N., Gerba, C. P., Oswald, A. \& Mashadi, F. D. Emerging waterborne pathogens: can we kill them all? Applied Environmental Microbiology. 71, 256-336, 2005.

[8] Benjamin, A. P. \& Brown, R. Encyclopedia of Food science and Nutrition. United Kingdoms: UK Academic Press, 2003. 
[9] Heydari, M. M. \& Bidgoli, H. N. Chemical analysis of drinking water of Kashan District, Central Iran. World Applied Sciences Journal. 16, 799$805,2012$.

[10] WHO. Guidelines for drinking water. 2nd Ed. Health Criteria and other supporting Information. Geneva, Switzerland: World Health Organization, 1996.

[11] Mulamattathil, S. G., Bezuidenhout, C. \& Mbewe, M. Analysis of physicochemical and bacteriological quality of drinking water in Mafikeng, South Africa. Water and Health. 13, 1143-1152, 2015.

[12] WHO. Guidelines for Drinking Water Quality. Geneva, Switzerland: World Health Organization, 2011.

[13] Hsieh, J. L., Nguyen, T. Q., Matte, T. \& Ito, K. Drinking Water Turbidity and Emergency Department Visits for Gastrointestinal Illness in New York City, 2002-2009. PLOS ONE. 4, 1-16, 2015.

[14] Momba, M. N. B., Tyafa, Z. \& Makala, N. Rural water treatment plants fail to provide potable water to their consumers: the Alice water treatment plant in the Eastern Cape province of South Africa. South African Journal of Science. 6, 307-310, 2004.

[15] Rahmanian, N., Hajar, S., Homayoonfard, M., Ali, N. J., Rehan, M., Sadef, Y. \& Nizami, A. S. Analysis of Physiochemical Parameters to Evaluate the Drinking Water Quality in the State of Perak, Malaysia. Journal of Chemistry. 1, 1-10, 2015.

[16] Kavcar, P., Sofuoglu, A. \& Sofuoglu, S. C. A health risk assessment for exposure to trace metals via drinking water ingestion pathway. International Journal of Hygiene and Environmental Health. 12, 216-227, 2009. 